\title{
Mananoligossacarídeo em dietas para leitões desmamados
}

\author{
Mannanoligosacharide in diets for weaning pigs
}

\author{
Susana Zaneti da SILVA'; Maria Cristina THOMAZ1; Pedro Henrique WATANABE'; Rizal Alcides \\ ROBLES HUAYNATE ${ }^{1}$; Urbano dos Santos RUIZ ${ }^{1}$; Leonardo Augusto Fonseca PASCOAL ${ }^{1}$; Vivian \\ Maia dos SANTOS ${ }^{1}$; Guido Carlos Iselda Hermans MASSON ${ }^{1}$ \\ ${ }^{1}$ Faculdade de Ciências Agrárias e Veterinárias da Universidade Estadual Paulista, Jaboticabal -SP, Brasil
}

\begin{abstract}
Resumo
Foi realizado um ensaio com o objetivo de avaliar o uso de mananoligossacarídeo (MOS) em dietas para leitões na fase de creche, quanto ao desempenho, incidência de diarreia e parâmetros sanguíneos. Foram comparados diferentes níveis de $\operatorname{MOS}(0,0,1$ e 0,2\%) em dietas para leitões desmamados aos 21 dias de idade com peso de 5,28 $\pm 0,90 \mathrm{~kg}$, sendo utilizados 72 animais da linhagem comercial Topigs ( 36 machos castrados e 36 fêmeas). Utilizou-se o delineamento em blocos ao acaso para controlar diferenças iniciais de peso. Os resultados demonstraram que a inclusão de MOS nas dietas de leitões recém desmamados não promoveu melhoras no ganho diário de peso, no consumo diário de ração e na conversão alimentar. Embora tenha sido observada redução na incidência de diarreia nos animais alimentados com dieta contendo $0,2 \%$ de MOS, a adição deste prebiótico não proporcionou melhores desempenho e resposta imunológica dos leitões. Com estes resultados, não é possível recomendar a adição de nenhum nível do produto avaliado.
\end{abstract}

Palavras-chave: Diarreia. Fase de creche. Imunoglobulinas. Prebiótico. Sus scrofa.

\begin{abstract}
An assay was carried out to evaluate the use of mannanoligosaccharide (MOS) in piglet diets on performance, diarrhea incidence and blood parameters. Different levels of MOS inclusion $(0,0.1$ and $0.2 \%)$ for pig diets were compared. A total of 72 piglets of Topigs lineage weaned at 21 days of age with $5.28 \pm 0.90 \mathrm{~kg}$ of live weight were used. It was used a randomized block design to control differences between initial weights of replicates. The results show that MOS inclusion in weaning pig diets did not promote better results on daily weight gain, daily feed intake and feed conversion. Although reduction in diarrhea incidence was observed in animals fed with $0.2 \%$ MOS diet, this prebiotic did not improve the immune response of piglets. Any level of MOS evaluated is recommended for piglets.
\end{abstract}

Keywords: Diarrhea. Immunoglobulins. Post-weaning. Prebiotic. Sus scrofa.

\section{Introdução}

O desmame de leitões é uma fase crítica na produção de suínos, por reunir diversos fatores que podem prejudicar o desenvolvimento dos animais. Por ocasião do desmame, a mudança de alimento, a forma física da ração, a variação na proporção dos nutrientes, bem como o estresse de ordem social, ocasionam mudanças estruturais no trato gastrintestinal (TGI), resultando em baixos consumo e aproveitamento de alimentos, com alta susceptibilidade à ocorrência de infecções entéricas nas primeiras semanas após o desmame, ocasionando baixo desempenho e, muitas vezes, alta taxa de mortalidade dos animais.

Durante muitas décadas, foram utilizados os antibióticos, em doses subterapêuticas, como promotores de crescimento, obtendo-se melhores índices zootécnicos pela diminuição ou eliminação de microrganismos prejudiciais ao TGI. Porém, a crescente restrição ao uso de antibióticos como promotores de crescimento na nutrição animal, fez com que surgisse uma nova geração de produtos para auxiliar no equilíbrio benéfico da microbiota do TGI, dentre os quais, os prebióticos, que são oligossacarídeos não digeridos

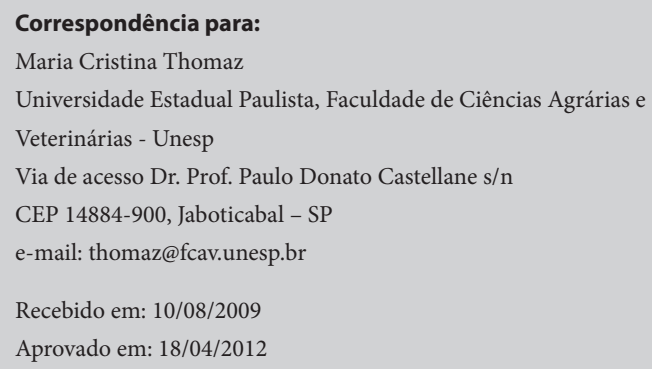


por enzimas, sais ou ácidos produzidos pelo organismo animal, mas seletivamente fermentados pelos microrganismos do TGI, podendo estar presentes nos ingredientes da dieta ou adicionados a ela por meio de fontes exógenas concentradas ${ }^{1,2}$.

Os prebióticos mais importantes são formados por hexoses como glicose, frutose, galactose, manose e pentoses como ribose, xilose e arabinose, sendo que frutose e manose são os componentes dos dois mais importantes grupos de prebióticos utilizados atualmente: frutoligossacarídeo (FOS) e mananoligossacarídeo (MOS), respectivamente ${ }^{1}$. Embora o FOS seja utilizado em estudos na nutrição animal devido à sua ação prebiótica, a competição por seu uso na alimentação humana dificulta sua utilização, enquanto o MOS apresenta-se disponível por ser obtido do processamento do resíduo da indústria sucroalcooleira.

De acordo com Spring et al. ${ }^{3}$, o MOS apresenta ação prebiótica por aumentar a resistência contra doenças entéricas e promover o crescimento do animal, inibindo a colonização por patógenos entéricos ao bloquear os sítios de adesão de bactérias patogênicas no intestino, ocupando o sítio de ligação da lectina nas fímbrias das mesmas.

Uma vez que os prebióticos estimulam o crescimento e a atividade de bactérias benéficas, promovendo ainda melhorias no ambiente e no epitélio intestinal, espera-se que o uso desses compostos também se reflita de forma desejável no desempenho de suínos na fase de creche. Ao fornecer MOS em dietas para leitões durante quatro semanas na fase de creche, Van der Beke $^{4}$ observou melhora de $7,4 \%$ no ganho de peso e $5,2 \%$ na eficiência alimentar. Brendemuhl e Harvey ${ }^{5}$, fornecendo 0,2\% de MOS para leitões dos 10 aos 28 $\mathrm{kg}$ de peso, observaram maiores ganho diário de peso e consumo diário de ração, quando comparado com o fornecimento de $0,1 \%$ do mesmo prebiótico.

No entanto, como os resultados positivos sobre o desempenho animal com adição de compostos de ação prebiótica às dietas nem sempre são evidencia- dos, supõe-se que esta falta de resposta possa estar vinculada a um efeito diluidor dos polissacarídeos não amiláceos oriundos dos ingredientes da dieta. Outro fator a ser considerado é que os compostos mais usados atualmente como prebióticos não são tão seletivos, isto é, eles não são fermentados somente por bifidobactérias e/ou lactobacillus, mas também por populações potencialmente patogênicas ${ }^{6,7}$, o que diminui o seu efeito benéfico.

Esta falta de resultados positivos também pode estar relacionada com a composição dos ingredientes presentes na dieta, com a dosagem adicionada, com a adaptação e a seletividade da microbiota ao prebiótico ou com o nível de estresse do animal ${ }^{8}$.

Nesse sentido, os objetivos deste trabalho foram avaliar os efeitos da adição de diferentes níveis de mananoligossacarídeo (MOS) nas rações de leitões recém desmamados, quanto ao desempenho (ganho diário de peso, consumo diário de ração e conversão alimentar), a incidência de diarreia e os parâmetros sanguíneos (hemograma, leucograma e proteínas séricas).

\section{Material e Método}

O ensaio foi conduzido no Setor de Suinocultura do Departamento de Zootecnia da Faculdade de Ciências Agrárias e Veterinárias, UNESP - Campus de Jaboticabal, no período de fevereiro a abril de 2006, sendo utilizados 72 leitões, 36 machos castrados e 36 fêmeas, de mesma linhagem comercial (Topigs), desmamados aos 21 dias de idade, com peso de $5,28 \pm 0,90 \mathrm{~kg}$.

Os animais foram alojados em 36 baias de alvenaria, sendo um macho e uma fêmea em cada baia. As baias eram de piso compacto e mediam 2,55 $\mathrm{m}^{2}$ cada, sendo dotadas de bebedouros do tipo vaso comunicante, comedouros semiautomáticos e escamoteadores de madeira, com aquecimento por lâmpadas incandescentes.

Os leitões foram distribuídos entre três tratamentos experimentais, sendo: Dieta controle (DC); 
$\mathrm{DC}+0,1 \% \mathrm{MOS}$ e $\mathrm{DC}+0,2 \% \mathrm{MOS}$. As dietas eram isonutritivas e isentas de qualquer produto com ação promotora de crescimento, sendo compostas principalmente por milho, farelo de soja e produtos lácteos e estão representadas na tabela 1 , seguindo as exigências nutricionais mínimas dos animais recomendadas por Rostagno et al. ${ }^{9}$, para as fases: $1-$ dos 21 aos 31 dias, 2 - dos 32 aos 42 dias e 3 - dos 43 aos 63 dias de idade.

Dos 21 aos 42 dias de idade (fases 1 e 2), os leitões consumiram ração contendo prebiótico e, dos 43 aos 63 dias (fase 3), todos receberam a mesma ração sem adição do produto. A ração desperdiçada dos comedouros era recolhida antes da limpeza diária das baias, quantificada e descontada do consumo.

Foram avaliados o ganho diário de peso, o consumo diário de ração e a conversão alimentar, a partir dos valores de peso corporal e consumo de ração. Como não houve redistribuição dos animais nos blocos ao final de cada fase, os resultados são apresentados nos seguintes períodos: 1 - dos 21 aos 31 dias de idade, 2 - dos 21 aos 42 dias de idade e 3 - dos 21 aos 63 dias de idade.

Tabela 1 - Composições percentuais e níveis nutricionais das dietas controle de acordo com as fases 1,2 e 3

\begin{tabular}{|c|c|c|c|}
\hline Ingredientes & Fase 1 & Fase 2 & Fase 3 \\
\hline Milho & 47,09 & 54,40 & 66,52 \\
\hline Farelo de soja & 32,98 & 32,63 & 29,42 \\
\hline Soro de leite em pó & 10,00 & 5,00 & - \\
\hline Açúcar & 2,16 & 1,00 & - \\
\hline Óleo de soja & 3,00 & 2,94 & 0,74 \\
\hline Fosfato bicálcico & 2,19 & 1,74 & 1,63 \\
\hline Inerte $^{(1)}$ & 0,20 & 0,20 & - \\
\hline Calcário Calcítico & 0,47 & 0,70 & 0,60 \\
\hline Sal comum & 0,47 & 0,44 & 0,46 \\
\hline L-Treonina (95\%) & 0,34 & 0,20 & 0,10 \\
\hline L-Lisina.HCl (78\%) & 0,76 & 0,51 & 0,36 \\
\hline DL-Metionina (99\%) & 0,17 & 0,10 & 0,05 \\
\hline L-Triptofano (98\%) & 0,05 & 0,02 & - \\
\hline Suplemento mineral e vitamínico ${ }^{(2)}$ & 0,10 & 0,10 & 0,10 \\
\hline Antioxidante (BHT) & 0,02 & 0,02 & 0,02 \\
\hline Total & 100,0 & 100,0 & 100,0 \\
\hline \multicolumn{4}{|l|}{ Valores calculados ${ }^{(3)}$} \\
\hline Energia metabolizável (kcal/kg) & 3225 & 3225 & 3230 \\
\hline Proteína bruta (\%) & 20,00 & 20,00 & 19,24 \\
\hline Cálcio (\%) & 0,89 & 0,80 & 0,72 \\
\hline Fósforo total (\%) & 0,76 & 0,66 & 0,62 \\
\hline Fósforo disponível (\%) & 0,56 & 0,45 & 0,40 \\
\hline Sódio (\%) & 0,28 & 0,23 & 0,20 \\
\hline Lisina digestível (\%) & 1,52 & 1,33 & 1,15 \\
\hline Metionina digestível (\%) & 0,43 & 0,37 & 0,32 \\
\hline Triptofano digestível (\%) & 0,26 & 0,23 & 0,20 \\
\hline Treonina digestível (\%) & 0,96 & 0,84 & 0,72 \\
\hline Lactose (\%) & 9,62 & 4,81 & - \\
\hline
\end{tabular}

(1) O probiótico testado foi incluído em substituição ao inerte, nas proporções de 0; 0,1 e 0,2\% nas rações das fases 1 e 2 ${ }^{(2)} \mathrm{O}$ suplemento mineral e vitamínico não continha qualquer tipo de promotor de crescimento ou antibiótico. Níveis de garantia por quilo de ração: Vit. A - 4.000U.I. Vit. D3 - 220 U.I. Vit. E - 22mg: Vit. K - 0,5mg: Vit. B2 - 3,75 mg: Vit. B12 - $20 \mu \mathrm{g}$.

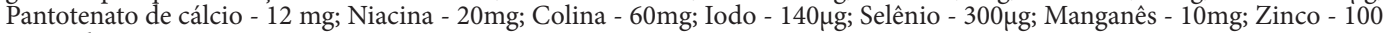
mg; Cobre - $10 \mathrm{mg}$; Ferro - $99 \mathrm{mg}$

(3) Rostagno et al. (2005) 
A incidência de diarreia foi avaliada mediante a verificação visual diária das fezes dos animais, realizada no mesmo horário e pela mesma pessoa, durante os primeiros 20 dias de experimento, conforme procedimento descrito por Vassalo et al. ${ }^{10}$. Foi utilizado o seguinte critério para os escores fecais: 1 - fezes com consistência normal; 2- fezes pastosas e 3- fezes moles ou aquosas, sendo 1 e 2 considerados fezes normais e 3 como presença de diarreia.

Para avaliação dos parâmetros sanguíneos dos animais, foram realizadas três colheitas de sangue de um mesmo animal sorteado por baia, aos 21, 31 e 42 dias de idade, sendo analisados o hemograma, o leucograma e as proteínas séricas. Para os hemograma e leucograma, foram colhidos $2 \mathrm{~mL}$ de sangue por punção do sinus orbital, sendo colocados em tubos contendo anticoagulante (EDTA). Por meio do hemograma, determinaram-se as concentrações de hemácias $\left(10^{3} /\right.$ $\mu \mathrm{L})$, leucócitos $(\mu \mathrm{L})$, hemoglobina ( $\mathrm{g} / \mathrm{dL})$ e hematócrito (\%). Foi realizada a contagem diferencial de leucócitos, calculando-se as percentagens de eosinófilos, neutrófilos bastonetes, neutrófilos segmentados, linfócitos e monócitos.

Para a avaliação das proteínas séricas, foram colhidos $4 \mathrm{~mL}$ de sangue, por meio de punção do sinus orbital, sendo as amostras centrifugadas e, no soro resultante, avaliadas as concentrações de proteínas séricas totais, albumina e por eletroforese convencional, foram obtidas as frações proteicas (alfa, beta 1 , beta 2, gama, beta+gama globulinas e globulinas totais). Todos os procedimentos analítico-laboratoriais foram realizados nas dependências do Laboratório de Patologia Clínica do Hospital Veterinário da Faculdade de Ciências Agrárias e Veterinárias, Unesp - Campus de Jaboticabal.

Foi utilizado o delineamento em blocos ao acaso, para controlar as diferenças iniciais de peso, com três tratamentos, 12 repetições por tratamento $\mathrm{e}$ dois animais por unidade experimental. Os dados de desempenho foram analisados por meio do pro- cedimento "General Linear Model" (GLM) do software estatístico Statical Analysis System $\left(\mathrm{SAS}^{11}\right)$ e as médias comparadas pelo teste de Tukey (5\%). Para a análise estatística dos dados de incidência de diarreia, utilizou-se o teste não paramétrico de KruskallWallis (5\%). Na análise dos parâmetros sanguíneos (hemograma, leucograma e proteínas séricas), foi utilizado o delineamento em parcela subdividida, sendo as parcelas os níveis de MOS e as subparcelas os dias de colheita. Para a porcentagem de eosinófilos, os dados foram transformados por $(\mathrm{Y}+0,5)^{1 / 2}$. Os dados dos parâmetros sanguíneos foram comparados pelo teste de Tukey (5\%).

\section{Resultados e Discussão}

As médias de ganho diário de peso (GDP), consumo diário de ração (CDR) e conversão alimentar (CA) dos leitões em função dos níveis de MOS nas dietas, nos períodos 1,2 e 3 , são apresentadas na tabela 2 . Observou-se que, no período 1, o GDP dos leitões foi maior $(\mathrm{P}<0,05)$ quando receberam a $\mathrm{DC}$, enquanto no 2, foi constatada diferença $(\mathrm{P}<0,05)$ apenas entre DC e DC+0,1\%MOS, não sendo afetado $(P>0,05)$ no período 3. O CDR não foi afetado $(\mathrm{P}>0,05)$ em nenhum dos períodos avaliados.

A CA foi afetada $(\mathrm{P}<0,05)$ nos três períodos estudados, sendo que no período 1 , observou-se diferença $(\mathrm{P}<0,05)$ apenas entre os leitões recebendo DC e DC+0,1\%MOS, e nos períodos 2 e 3 , os animais que consumiram as dietas DC e DC+0,2\%MOS apresentaram conversões melhores $(\mathrm{P}<0,05)$ quando comparados àqueles que receberam $\mathrm{DC}+\% 0,1 \mathrm{MOS}$.

O uso de MOS e outros oligossacarídeos como prebióticos para leitões desmamados tem sido estudado na procura por possíveis alternativas aos antibióticos promotores de crescimento. Embora algumas pesquisas tenham evidenciado que a adição de MOS nas dietas promoveu melhora no desempenho dos leitões ${ }^{4,12}$, observou-se também que há um questionamento 
Tabela 2 - Valores médios e desvios padrão das médias de ganho diário de peso (GDP), consumo diário de ração (CDR) e conversão alimentar (CA) dos leitões, em função dos níveis de inclusão de MOS nas dietas, nos períodos 1, 2 e 3

\begin{tabular}{lcccc}
\hline Estatística & $\mathrm{DC}^{(1)}$ & $\mathrm{DC}+0,1 \% \mathrm{MOS}$ & $\mathrm{DC}+0,2 \% \mathrm{MOS}$ & $\mathrm{CV}, \%^{(2)}$ \\
\hline Período 1 (21-31 dias) & & & & \\
GDP (g) & $80 \pm 60 \mathrm{a}$ & $30 \pm 10 \mathrm{~b}$ & $40 \pm 20 \mathrm{~b}$ & 65,34 \\
CDR (g) & $160 \pm 50$ & $140 \pm 20$ & $150 \pm 50$ & 19,10 \\
CA & $3,31 \pm 0,23 \mathrm{a}$ & $6,05 \pm 0,33 \mathrm{~b}$ & $4,79 \pm 0,25 \mathrm{ab}$ & 57,05 \\
Período 2 (21-42 dias) & & & & \\
GDP (g) & $140 \pm 70 \mathrm{a}$ & $110 \pm 50 \mathrm{~b}$ & $130 \pm 50 \mathrm{ab}$ & 26,28 \\
CDR (g) & $240 \pm 80$ & $210 \pm 50$ & $230 \pm 70$ & 15,89 \\
CA & $1,88 \pm 0,04 \mathrm{a}$ & $2,21 \pm 0,06 \mathrm{~b}$ & $1,80 \pm 0,02 \mathrm{a}$ & 19,52 \\
Período 3 (21-63 dias) & & & & \\
GDP (g) & $260 \pm 50$ & $230 \pm 40$ & $260 \pm 40$ & 13,27 \\
CDR (g) & $450 \pm 80$ & $430 \pm 60$ & $440 \pm 70$ & 10,90 \\
CA & $1,72 \pm 0,02 \mathrm{a}$ & $1,85 \pm 0,02 \mathrm{~b}$ & $1,72 \pm 0,01 \mathrm{a}$ & 7,67 \\
\hline
\end{tabular}

Médias seguidas de mesmas letras nas linhas não diferem entre si pelo teste de Tukey $(\mathrm{P}>0,05) .{ }^{(1)} \mathrm{DC}$ - dieta controle. ${ }^{(2)}$ coeficiente de variação

quanto ao seu uso em função de resultados que não mostram o mesmo efeito sobre os leitões ${ }^{13}$.

Diante de tal colocação, o primeiro fator a ser considerado é que os compostos mais usados atualmente como prebióticos não são tão seletivos, isto é, eles não são fermentados somente por bifidobactérias e/ ou lactobacilos, mas também por populações potencialmente patogênicas ${ }^{6,7}$, o que diminui o seu efeito benéfico. Tem sido evidenciado também que níveis acima de $0,2 \%$ na dieta são necessários para que o efeito quelante do MOS sobre as bactérias seja potencializado $^{14,15}$, havendo possível relação com o primeiro fator citado.

Os resultados observados neste experimento discordaram dos obtidos por Van der Beke ${ }^{4}$, que encontrou melhora de $7,4 \%$ no ganho de peso e $5,2 \%$ na eficiência alimentar, quando forneceu MOS nas dietas de leitões durante 4 semanas na fase de creche e também dos notados por Brendemuhl e Harvey ${ }^{5}$, que forneceram $0,2 \%$ de MOS para leitões e observaram maiores ganho diário de peso e consumo diário de ração, quando comparado com o fornecimento de $0,1 \%$ do mesmo prebiótico.

Os dados de escores fecais dos leitões recém desmamados em função dos níveis de prebiótico (MOS) são apresentados na tabela 3. Embora tenha proporcionado redução $(\mathrm{P}<0,05)$ na incidência de diarreia, em relação aos leitões recebendo DC, a adição de $0,1 \%$ de MOS na dieta não se mostrou tão eficiente quando comparada com a inclusão de $0,2 \%$ do prebiótico.

A diarreia é um sintoma diretamente relacionado com a queda de desempenho e aumento da mortalidade de leitões e a sua menor prevalência, quando houve a inclusão de MOS nas dietas, pode ser um indicativo de melhor resposta imunofisiológica dos animais frente aos microrganismos patogênicos. Nesse sentido, White et al. ${ }^{16}$ estudaram o efeito da adição de $0,16 \%$ de MOS em dietas para leitões sobre a microbiota intestinal e observaram redução no número de coliformes totais e aumento no número de lactobacilos nos conteúdos do duodeno e jejuno, afirmando que a inibição do desenvolvimento de coliformes pode ser uma forma de diminuir ou ainda prevenir a diarreia pós-desmame.

Grela et al. ${ }^{15}$ ao avaliarem a adição de $0,3 \%$ de MOS em dietas para leitões desmamados aos 28 dias de idade, afirmaram que o uso do prebiótico não apenas ocasionou menor incidência de diarreia, mas também promoveu melhor resposta no desempenho dos animais. Entretanto, no presente trabalho, as menores 
Tabela 3 - Escores fecais e percentagens de diarréia dos leitões em função dos níveis de MOS nas dietas

\begin{tabular}{lccccc}
\hline Escore & DC & DC +0,1\%MOS & DC+0,2\%MOS & Total & \% de escore \\
\hline 1 & 201 & 218 & 257 & 676 & 48,56 \\
2 & 129 & 139 & 143 & 411 & 29,53 \\
3 & 133 & 101 & 71 & 305 & 21,91 \\
Total & 463 & 458 & 471 & 1392 & 100,00 \\
\% escore $3^{*}$ & $28,73 \mathrm{c}$ & $22,05 \mathrm{~b}$ & $15,07 \mathrm{a}$ & - & - \\
\hline
\end{tabular}

Médias seguidas de mesmas letras na linha, não diferem pelo teste do Kruskal-Wallis (5\%); * percentagem de fezes diarréicas

percentagens de diarreia observadas quando houve as adições de 0,1 e 0,2\% de MOS não foram acompanhadas de melhores respostas nos parâmetros de desempenho. Castillo et al. ${ }^{17}$ afirmaram que a inclusão de baixos níveis de prebióticos nas dietas para leitões, comparados aos dos carboidratos não digestíveis, como amido resistente ou polissacarídeos não-amiláceos dos cereais presentes nestas dietas, pode diminuir o potencial fermentativo benéfico destes componentes.

Os resultados das análises sanguíneas para proteínas séricas, hemograma e leucograma em função da inclusão dos níveis de MOS nas dietas e dias de colheita estão apresentados na tabela 4. Os resultados mostraram que dentro das dietas $(\mathrm{N})$, apenas a PST e a Glob $\beta 2$ não foram afetadas $(\mathrm{P}>0,05)$ e dentro dos dias de colheita, não foram alteradas $(P>0,05)$ a PST e as Glob a e $\beta 2$. Houve interação $(\mathrm{P}<0,05)$ para PST, Alb, Glob T, $\alpha, \beta 2$ e $\beta+\gamma$ (Tabela 5). Verificou-se efeito $(P<0,05)$ dos níveis de MOS sobre $\mathrm{He}, \mathrm{Hb}$ e Ht e dos dias de colheita sobre $\mathrm{He}, \mathrm{Hb}, \mathrm{Ht}$, Le e NBas. Não foi observada interação significativa para nenhuma das características do hemograma e leucograma avaliadas.

As concentrações sanguíneas de proteínas totais, albumina e globulina podem ser utilizadas para se avaliar o metabolismo proteico dos animais e, nesse sentido, as reduções observadas para proteínas totais e albumina em função dos dias de colheita para os animais alimentados com dietas contendo $0,1 \%$ de MOS pode ser um indicativo de que houve maior catabolismo proteico, ocasionando menor disponibilidade de aminoácidos para o desenvolvimento do animal e, consequentemente, menor desempenho.

As concentrações de Glob $\beta 1$ e $\beta 2$ tendem a aumentar com a ocorrência de doenças inflamatórias e as de Glob $\gamma$ com doenças infecciosas ${ }^{18}$. Assim, as maiores concentrações de Glob $\beta 1$ e Glob $\gamma$, indicaram que a adição de $0,1 \%$ de MOS nas dietas não promoveu melhor resposta imunológica frente ao desafio existente, havendo uma possível correlação com o pior desempenho dos leitões encontrado nos períodos 1 e 2, com a inclusão desse nível de prebiótico.

As variações existentes para as características do hemograma e leucograma podem ser devidas ao desmame, em função do estresse naturalmente presente neste período ou ainda pela manipulação do animal no momento da colheita ${ }^{19}$. Os resultados obtidos anteriormente por Jiang et al. ${ }^{20}$ e Budiño et al. ${ }^{21}$, concordaram com os valores observados neste estudo, sendo encontrado aumento no número de leucócitos com o aumento da idade dos animais pós-desmame.

Para as características de hemograma, observou-se que os leitões que receberam rações contendo MOS apresentaram aumentos nas concentrações de hemácias e hemoglobina em relação àqueles do tratamento sem MOS, sendo encontrada ainda maior porcentagem de hematócrito nos animais alimentados com $0,1 \%$ de MOS, quando comparados com os dos demais tratamentos. Grela et al. ${ }^{15}$ ao avaliarem a adição de 0,3\% de MOS em dietas para leitões, também observaram maior número de células vermelhas nos 
Tabela 4 - Médias de proteínas séricas e das características do hemograma e leucograma de leitões em função da inclusão dos níveis de MOS nas dietas (N) e dias de colheita (D)

\begin{tabular}{|c|c|c|c|c|c|c|c|c|c|c|}
\hline \multirow[b]{2}{*}{ Variáveis ${ }^{(1)}$} & \multicolumn{3}{|c|}{ Níveis $(\mathrm{N})$} & \multicolumn{3}{|c|}{ Dias de colheita (D) } & \multirow[b]{2}{*}{$\mathrm{CV}, \%$} & \multicolumn{3}{|c|}{ Efeito } \\
\hline & DC & $\begin{array}{l}\text { DC+ } \\
0,1 \% \\
\text { MOS }\end{array}$ & $\begin{array}{l}\text { DC+ } \\
0,2 \% \\
\text { MOS } \\
\end{array}$ & 21 & 42 & 63 & & $\mathrm{~N}$ & $\mathrm{D}$ & $\begin{array}{c}\mathrm{Nx} \\
\mathrm{D}\end{array}$ \\
\hline PST (g/dL) & 4,77 & 5,36 & 5,45 & 5,40 & 5,49 & 4,69 & 14,24 & ns & ns & * \\
\hline Alb (g/dL) & $2,27 b$ & $2,56 a$ & $2,64 a$ & $2,54 \mathrm{a}$ & $2,71 \mathrm{a}$ & $2,21 b$ & 15,62 & * & * & * \\
\hline Glob T (g/dL) & $2,53 b$ & $2,80 \mathrm{a}$ & $2,79 a$ & $2,85 \mathrm{a}$ & $2,79 \mathrm{a}$ & $2,48 b$ & 15,66 & * & * & * \\
\hline Glob a (g/dL) & $1,09 \mathrm{~b}$ & $1,09 b$ & $1,21 \mathrm{a}$ & 1,11 & 1,19 & 1,09 & 18,84 & * & ns & * \\
\hline Glob $\beta 1$ (g/dL) & $0,24 \mathrm{~b}$ & $0,32 \mathrm{a}$ & $0,28 \mathrm{ab}$ & $0,35 \mathrm{a}$ & $0,29 b$ & $0,20 c$ & 32,63 & * & * & ns \\
\hline Glob $\beta 2(\mathrm{~g} / \mathrm{dL})$ & 0,62 & 0,70 & 0,68 & 0,69 & 0,68 & 0,63 & 22,33 & ns & ns & * \\
\hline Glob $\gamma(\mathrm{g} / \mathrm{dL})$ & $0,57 b$ & $0,69 a$ & $0,62 \mathrm{ab}$ & $0,69 \mathrm{a}$ & $0,65 \mathrm{a}$ & $0,54 \mathrm{~b}$ & 22,73 & * & * & ns \\
\hline$\beta+\gamma(\mathrm{g} / \mathrm{dL})$ & $1,44 \mathrm{~b}$ & $1,71 \mathrm{a}$ & $1,58 \mathrm{ab}$ & $1,73 \mathrm{a}$ & $1,61 \mathrm{a}$ & $1,38 \mathrm{~b}$ & 18,17 & * & $*$ & * \\
\hline $\mathrm{He}\left(10^{3} / \mu \mathrm{L}\right)$ & $5567 \mathrm{~b}$ & $6000 \mathrm{a}$ & $5707 a$ & $5342 \mathrm{~b}$ & $6083 a$ & $5949 a$ & 11,29 & $*$ & $*$ & $\mathrm{~ns}$ \\
\hline $\mathrm{Hb}(\mathrm{g} / \mathrm{dL})$ & $10,11 \mathrm{c}$ & $11,17 \mathrm{a}$ & $10,65 b$ & $10,24 \mathrm{~b}$ & $11,17 \mathrm{a}$ & $10,53 b$ & 8,12 & * & * & ns \\
\hline Ht (\%) & $31,41 \mathrm{~b}$ & $34,61 \mathrm{a}$ & $32,33 b$ & $31,10 \mathrm{~b}$ & $34,55 \mathrm{a}$ & $32,70 \mathrm{ab}$ & 10,42 & * & $*$ & ns \\
\hline Le $(\mu \mathrm{L})$ & 16958 & 17903 & 17514 & $13383 b$ & $18225 \mathrm{a}$ & $20767 a$ & 27,90 & ns & $*$ & $\mathrm{~ns}$ \\
\hline $\operatorname{EOS}(\%)^{(2)}$ & 1,06 & 1,02 & 1,01 & 1,03 & 1,00 & 1,05 & 33,96 & ns & ns & $\mathrm{ns}$ \\
\hline NBas (\%) & 1,80 & 2,30 & 2,50 & $2,05 \mathrm{~b}$ & $3,39 a$ & $1,17 \mathrm{~b}$ & 71,86 & ns & $*$ & $\mathrm{~ns}$ \\
\hline NSeg (\%) & 42,19 & 46,61 & 45,05 & 43,86 & 45,05 & 44,94 & 23,74 & ns & ns & $\mathrm{ns}$ \\
\hline LINF (\%) & 49,83 & 47,19 & 47,83 & 48,86 & 46,19 & 49,80 & 22,62 & ns & ns & ns \\
\hline MON (\%) & 4,64 & 3,72 & 3,94 & 4,50 & 4,53 & 3,28 & 69,70 & ns & ns & ns \\
\hline
\end{tabular}

Médias seguidas de mesmas letras na linha, dentro de níveis (N) ou dentro de dias de colheita (D), não diferem entre si pelo teste de Tukey $(\mathrm{P}>0,05) .{ }^{\star}$ Efeito significativo $(\mathrm{P}<0,05) . \mathrm{ns}=$ não significativo. ${ }^{(1)} \mathrm{PST}=$ proteínas séricas totais, $\mathrm{Alb}=$ albumina, $\mathrm{Glob} \mathrm{T}=$ globulinas totais, Glob $\alpha=$ globulina $\alpha$, Glob $\beta 1=$ globulina beta 1 , Glob $\beta 2=$ globulina beta 2 , Glob $\gamma=$ globulina gama, $\beta+\gamma=$ globulinas beta + gama,

$\mathrm{He}=$ hemácia, $\mathrm{Hb}=$ hemoglobina, $\mathrm{Ht}=$ hematócrito, Le = leucócito, $\mathrm{EOS}=$ eosinófilo, NBas = neutrófilo bastonete, NSeg = neutrófilo segmentado, $\mathrm{LINF}=$ linfócito, $\mathrm{MON}=$ monócito. ${ }^{(2)} \mathrm{A}$ variável $\mathrm{EOS}$ foi transformada por $(\mathrm{Y}+0,5)^{1 / 2}$

animais alimentados com dietas contendo prebiótico. De acordo com Pond e Maner (1974) apud Miyada 22 , os níveis de hemoglobina e hematócrito são indicativos do estado nutricional dos suínos quanto ao ferro. Embora trabalhando com prebióticos diferentes dos avaliados no presente trabalho, $\operatorname{Santos}^{23}$ observou que a suplementação das dietas com galactooligossacarídeo e polidextrose, aumentou não apenas o ferro sérico de ratos, mas também as concentrações de hemoglobina e hematócrito, sugerindo que os prebióticos têm efeito potencializador na absorção de ferro.

Por outro lado, para as características de leucograma, observou-se que a adição de MOS nas dietas não promoveu alterações nos números de linfócitos e neutrófilos nos leitões. De acordo com Roth ${ }^{24}$, o aumento no número de neutrófilos está associado como a primeira linha de defesa em casos de infecções clínica ou subclínica. Embora Davis et al. ${ }^{14}$, ao avaliarem a adi- ção de MOS em dietas para leitões, tenham observado que ao nível de $0,3 \%$ este prebiótico reduziu o número de neutrófilos, sugerindo uma menor prevalência inflamatória frente ao desafio existente em função do melhor desempenho também encontrado, Van der Peet-Schwering et al. ${ }^{25}$ não notaram alterações nos níveis de linfócitos e neutrófilos de leitões alimentados com dietas contendo 0,2\% de MOS. Assim, no presente trabalho, não houve aumento da imunidade dos leitões quando das adições de 0,1 e $0,2 \%$ de MOS, confirmando os resultados de desempenho observados.

\section{Conclusão}

A adição de MOS não proporcionou melhores desempenho e resposta imunológica dos leitões, não sendo possível recomendar a adição de nenhum nível do produto avaliado. 
Tabela 5 - Desdobramentos das interações entre níveis de MOS (N) e dias de colheita (D)

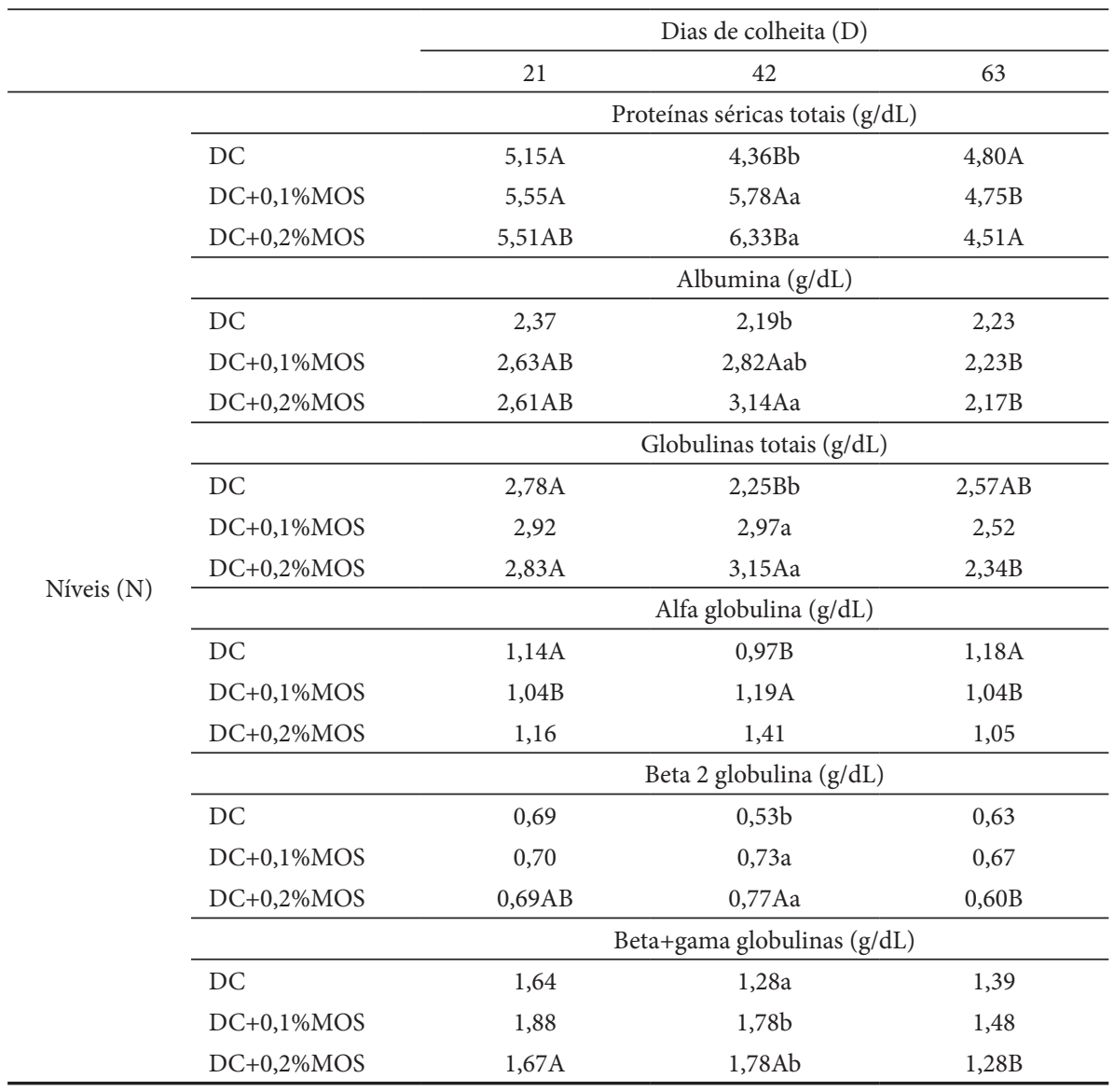

Médias seguidas de mesmas letras, maiúscula na linha e minúscula na coluna, não diferem entre si pelo teste de Tukey $(\mathrm{P}>0,05)$

\section{Referências}

1. GIBSON, G. R.; ROBERFROID, B. M. Dietary modulation of the human colonic microbiota: introducing the concept of prebiotics. Journal Nutrition, v. 125, n. 6, p. 1401-1412, 1995.

2. ROY, M.; GIBSON, G. R. Probiotics and prebiotics - microbial in menu. C-H-O Carbohydrates, v. 9, n. 3, p. 6, 1998. Disponível em: <http://www.babelfish.altavista.com/cgibm>. Acesso em: 16 jul. 2006

3.SPRING, P., WENK, C.; DAWSON, K. A.; NEWMAN, K. E. The effects of dietary mannanoligosaccharides on cecal parameters and the concentrations of enteric bacteria in the ceca of salmonella-challenged broiler chicks. Poultry Science, v. 79 , n. 2, p. 205-211, 2000.

4. VAN DER BEKE, N. The use of mannanoligosaccharides (Bio-Mos) and lactic acid bacteria (Lacto-Sacc) in piglet feed. 1997. 187 p. Tese (PhD) - Department Biotechnological Sciences, Landscape Management and Agriculture, Gent, Belgium, 1997.

5. BRENDEMUHL, J. H.; HARVEY, M. R. Evaluation of BioMos (Mananoligosaccharide) in diets for pigs. Growth performance response during nursery and growingfinishing phases. Gainnesville: University of Florida, 1999. (Report to Alltech).
6. MITSUOKA, T. Intestinal flora and aging. Nutrition Reviews, v. 50, n. 12, p. 438-446, 1992.

7.MOSENTHIN, R.; BAUER, E. The potential use of prebiotics in pig nutrition. In: INTERNATIONAL SYMPOSIUM ON RECENT ADVANCES IN ANIMAL NUTRITION, 2000, Seoul. Proceedings... Seoul: Seoul National University, 2000. p. 515-528.

8. SILVA, L. P.; NÖRNBERG, J. L. Prebióticos na nutrição de não ruminantes. Ciência Rural, v. 33, n. 5, p. 55-65, 2003.

9. ROSTAGNO, H. S.; ALBINO, L. F. T.; DONZELE, J. T. GOMES, P. C.; FERREIRA, A. S.; OLIVEIRA, R. F.; LOPES, D. C. Tabelas brasileiras para aves e suínos - Composição de alimentos e exigências nutricionais. Viçosa: Imprensa Universitária, 2005. 186 p.

10.VASSALO, M.; FIALHO, E. T.; OLIVEIRA, A. I. G.; TEIXEIRA, A. S.; BERTECHINI, A. G. Probióticos para leitões dos 10 aos $30 \mathrm{~kg}$ de peso vivo. Revista Brasileira em Zootecnia, v. 26, n. 1, p. 131-138, 1997.

11.STATISTICAL ANALISYS SYSTEM (SAS). SAS System for linear models. Cary: SAS Institute, 1998. 211 p.

12.PETTIGREW, J. E. Bio-Mos effects on pig performance: a review. In: BIOTECHNOLOGY IN FEED INDUSTRY 
OF ANNUAL SYMPOSIUM, 16., 2000, Nottingham. Proceedings... Nottingham: Nottingham University Press, 2000. p.31-44.

13.DAVIS, M. E.; MAXWELL, C. V.; KEGLEY, E. B.; RODAS, B. Z.; FRIESEN, K. G.; HELLWIG, D. H.; BROWN, D. C.; DVORACK, A. R. Efficacy of mannan oligosaccharide (Bio-Mos) supplementation with and without zinc oxide on performance and immunocompetence of weanling pigs. Journal of Animal Science, v. 78, p. 61, 2000. Supplement, 2.

14.DAVIS, M. E.; MAXWELL, C. V.; ERF, G. V.; BROWN, D. C.; WISTUBA, T. J. Dietary supplementation with phosphorylated mannans improves growth response and modulates immune function of weanling pigs. Journal of Animal Science, v. 82, n. 6, p. 1882-1891, 2004

15.GRELA, E. R.; SEMENIUK, V.; CZECH, A. Efficacy of fructooligosaccharides and mannanoligosaccharides in piglet diets. Medycyna Weterynaryjna, v. 62, pt. 7, p. 762-766, 2006.

16. WHITE, L. A.; NEWMAN, M. C.; CROMWELL, G. L.; LINDEMANN, M. D. Brewers dried yeast as a source of mannan oligosaccharides for weanling pigs. Journal of Animal Science, v. 80, n. 10, p. 2619-2628, 2002.

17.CASTILLO, M.; MARTÍN-ORÜE, S. M.; TAYLOR-PICKARD, J. A.; PEREZ, J. F.; GASA, J. Use of mannan-oligosaccharides and zinc chelate as growth promoters and diarrhea preventative in weaning pigs: effects on microbiota and gut function. Journal of Animal Science, v. 82, n. 1, p. 1882-1891, 2008.

18. KANEKO, J. J. Clinical biochemistry of domestic animals. 4. ed. California: Academic Press, 1989. p. 932.

19.SWENSON, M. J. Propriedades fisiológicas e constituintes celulares e químicos do sangue. In: SWENSON, M. J. (Ed.).
Dukes: fisiologia dos animais domésticos. 10. ed. Rio de Janeiro: Guanabara, 1984. p. 13-34

20.JIANG, R.; CHANG, X.; STOLL, B.; FAN, M. Z; ARTHINGTON, J.; WEAVER, E.; CAMPBELL, J.; BURRIN, D. Dietary plasma protein reduces small intestinal growth and lamina propria cell density in early weaned pigs. Journal Nutrition, v. 130, n. 1, p. 21-26, 2000.

21.BUDIÑO, F. E. L.; THOMAZ, M. C.; KRONKA, R. N.; NAKAGHI, L. S. O.; TUCCI, F. M.; FRAGA, A. L.; SCANDOLERA, A. J.; HUAYNATE, R. A. R. Effect of probiotic and prebiotic inclusion in weaned piglet diets on structure and ultra-structure of small intestine. Brazilian Archives of Biology and Technology, v. 48, n. 6, p. 921-929, 2005.

22. MIYADA, V. S. A levedura seca na alimentação de suínos: estudos adicionais sobre o seu valor protéico e vitamínico. 1987. 159 p. Tese (Livre Docência) - Escola Superior de Agricultura "Luiz de Queiroz", Piracicaba, 1987.

23.SANTOS, E. F. Efeito da suplementação de galactooligossacarídeo e polidextrose sobre a absorção de cálcio e ferro em ratos gastrectomizados. 2007. 82 p. Dissertação (Mestrado) - Universidade Estadual de Campinas, Campinas, 2007.

24.ROTH, J. A. The immune system. In: STRAW, B. E.; D'ALLAIRE, S.; MENGELING, W. L.; TAYLOR, D. J. (Ed.). Diseases of Swine. 8th ed. Iowa State University Press: Ames, 1999. p. 801-802.

25.VAN DER PEET-SCHWERING, C. M.; JANSMAN, A. J.; SMIDT, H.; YOON, I. Effects of yeast culture on performance, gut integrity, and blood cell composition of weanling pigs. Journal of Animal Science, v. 85, n. 11, p. 3099-3109, 2007. 